\title{
Study of Design Modification Effects through Performance Analysis of a Legacy Gas Turbine Engine
}

\author{
Gantayata Gouda1,2, Balaji Sankar, ${ }^{1, *}$ Venkat Iyengar1,2, Jana Soumendu1,2
}

Gantayata G (1) https: / / orcid. org/0000-0002-5464-1802
Sankar B (1) https: / / orcid. org/0000-0002-2771-5060
lyengar V (1) https: / / rcid. org/0000-0001-7669-0093
Soumendu J (D) https: / / orcid. org/0000-0003-2286-796X
How to cite

Gantayata G; Sankar B; lyengar V; Soumendu J (2020) Study of Design Modification Effects through Performance Analysis of a Legacy Gas Turbine Engine J Aerosp Tecnol Manag, 12: e0720. https://doi.org/10.5028/jatm.v12.1097

\begin{abstract}
Modifications to the critical parameters, such as the exhaust nozzle area, are sometimes done during maintenance of aircraft engines. These modifications are done either to increase the design thrust or to compensate for the reduction of thrust due to leakage in the variable area jet nozzle. There is a trade-off between several performance parameters when such critical parameters are changed during maintenance. A tuned aerothermodynamic simulation model that agrees well with the experimental data from the original engine is required to study the effect of these changes. In the present work, a multipoint map scaling approach and a parameter estimation method are used to develop a simulation model that agrees well with the experimental data from the original turbojet engine. The design modifications are then incorporated in the model, and the effect of the modification on the various performance parameters is studied. The effect of leakage in the nozzle flaps and the corresponding reduction required in the nozzle throat area are calculated. It is shown that the tuned model developed with experimental testbed data enables the identification of ancillary effects of a change in a design parameter, such as the nozzle throat area.
\end{abstract}

KEYWORDS: Aerothermodynamic model, Twin spool turbojet engine, Multipoint map scaling, Compressor characteristics map

\section{INTRODUCTION}

Aerothermodynamic simulation models predict gas path parameters at different stations along the engine.In these models, only a single pressure or temperature value can be calculated at a station on the engine. They do not account for the radial or circumferential variation of gas path parameters. These models are typically used in the design and development phases of engines,as well as during performance evaluation of legacy engines. They also find use in the Engine Health Monitoring systems, which monitor the overall performance characteristics of gas turbines in terms of component performance parameters.

In this study, an in-house aerothermodynamic simulation model (design point and off-design point) has been modified to simulate a legacy twin spool gas turbine engine. These engines are periodically overhauled after being used in the field. As part of the overhaul procedure, engines are tested to check if they meet the performance standards. Testbed data is available for many engines of the same variant from theground-based static test bed. This data is available with the overhauling agency. Since both the engines and the testbed are old (1970), there is no provision for continuous time series monitoring of various parameters. They are noted down manually from testbed instrumentation. This type of data set is shown in the normalized form in Table 1. The data set provides gas path temperatures and pressures along the engine. Using these measurements, the characteristics maps 
of an engine very similar to this one have been tuned, and are used to simulate the performance of the engine at cruise, nominal and max dry rating. Because of the use of a tuned characteristics map in simulation, the simulation model agrees well with the experimental data. This model is used to study the effect of a small reduction made in the exhaust area of the nozzle at full reheat rating. It is shown that, in addition to increasing the thrust of the engine, which was the original goal, the reduction of nozzle area also causes the high pressure spool of the twinspool turbojet to overspeed. It is hoped that the multipoint scaling techniques for compressor maps presented in this work will help in better tuning of engine models when testbed data is available.

Saravanamuttoo (1992) has described the use of aerothermodynamic simulation models in engine control system design and engine health monitoring. Details of engine performance and health monitoring models using steady state and transient performance prediction methods have been presented in by Isaac (1992). An adapted performance model has been used in the performance evaluation of the LM2500 industrial gas turbine, in the work reported by Bechini (2007) and Tsoutsanis (2010). A detailed review of the use of simulation models in performance analysis of gas turbines has been made by Li (2002). Limited information about the effect of various component degradations on the performance of the engine is available in the open literature, such as those given by Fasching (1982) and Kerrebrock (1992). In Sankar et al. (2015), the degradation that occurs in a turbojet engine during an extensive ground test over hundreds of hours is described. Several resources that detail the methodology of off- and on-design performance modeling of gas turbines are available, such as Mattingly (2006),Walsh et al. (2004), and Cohen et al.(2001). A significant hurdle in the development of these models for a legacy engine is the non-availability of realistic component characteristic maps and design data, such as bleed schedules, inter-duct losses, power off-take, and component geometry. Optimization-based and non-linear gas path analysis-based methods for the estimation of these component parameters have been presented by Li et al.(2006). For legacy engines, even design point parameters are often not available or the engine has degraded in such a way that the original design parameters are no longer achieved. Estimation of design point parameters from test bed data in such cases is presented in Sankar et al. (2016).

In the first place, this paper presents a brief description of the engine for which the model is being developed, followed by the characteristic map tuning process adopted to increase the accuracy of the simulation. An example of duct pressure loss and afterburner efficiency estimation is presented next. Using these component maps and estimated efficiencies, the off-design model is developed. After validation, the effect of reduction of exhaust area of the nozzle is simulated, and the results are plotted. The reason for the increase in RPM of HP spool is discussed in the conclusion.

\section{ENGINE DESCRIPTION}

The section view of the engine studied in this paper is shown in Fig. 1. The compressor of the engine is made up of a three-stage axial low pressure compressor and a five-stage axial high pressure compressor. The compressor does not have any provisions for variable inlet

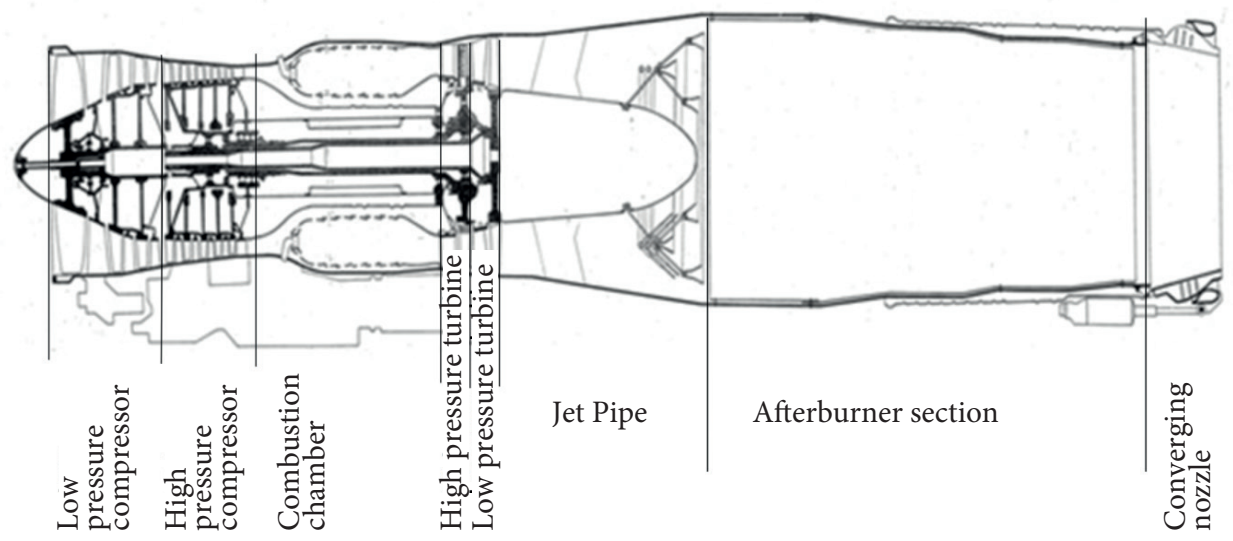

Figure 1. Section view of the turbojet engine showing major turbomachinery components. 
or stator vanes. However, special perforated casing is provided for the low pressure spool to increase the surge margin at the low flow rates in off-design ratings. The compressor also has blown-off valves at the end of HPC (high pressure compressor) to further increase the surge margin during the starting of the engine. The combustor is a ten tube can-annular combustor of a straight flow type. The turbine sare axial and use reaction type blading, which are cooled in the HPT (high pressure turbine). The exhaust nozzle area does not change during the dry ratings of the engines. During the reheat ratings, the area increases in proportion to the increase in specific volume to the flow.

\section{AVAILABLE EXPERIMENTAL DATA}

The available experimental data has been collected at max dry rating and two additional off-design ratings. Furthermore, data is also available at the three reheat ratings with different afterburner fuel flow levels and the exhaust nozzle area. The available data has been tabulated in the normalized form in Table 1 . The normalization is done with respect to the max dry rating, which is the design point of this engine. For $\mathrm{AB}$ (afterburner) fuel flow rate, the actual value in $\mathrm{kg} / \mathrm{s}$ is given as the $\mathrm{AB}$ fuel flow rate in dry max rating is zero.

Table 1. Normalized experimental data available.

\begin{tabular}{|c|c|c|c|c|c|c|}
\hline Parameter & $\begin{array}{c}\text { Full } \\
\text { reheat }\end{array}$ & $\begin{array}{l}\text { Partial } \\
\text { reheat }\end{array}$ & $\begin{array}{l}\text { Minimum } \\
\text { reheat }\end{array}$ & $\begin{array}{l}\text { Max dry } \\
\text { rating }\end{array}$ & $\begin{array}{l}\text { Nominal } \\
\text { rating }\end{array}$ & $\begin{array}{c}\mathbf{8 0} \% \text { of nominal } \\
\text { rating }\end{array}$ \\
\hline N1 & 1.00 & 1.00 & 1.00 & 1.00 & 0.94 & 0.89 \\
\hline $\mathrm{N} 2$ & 1.03 & 1.01 & 1.01 & 1.00 & 0.96 & 0.92 \\
\hline Thrust & 1.68 & 1.52 & 1.34 & 1.00 & 0.88 & 0.70 \\
\hline Thrust specific fuel consumption & 2.21 & 2.02 & 1.60 & 1.00 & 0.93 & 0.91 \\
\hline LPC outlet total pressure & 0.97 & 0.98 & 0.98 & 1.00 & 0.96 & 0.87 \\
\hline HPC outlet total pressure & 1.05 & 1.02 & 1.02 & 1.00 & 0.92 & 0.80 \\
\hline HPT outlet total pressure & 1.04 & 1.01 & 1.01 & 1.00 & 0.92 & 0.80 \\
\hline LPT outlet total pressure & 1.14 & 1.07 & 1.07 & 1.00 & 0.93 & 0.82 \\
\hline Jet pipe static pressure after $A B$ pressure loss & 1.17 & 1.09 & 1.09 & 1.00 & 0.94 & 0.90 \\
\hline LPC outlet total temperature & 0.99 & 0.99 & 0.99 & 1.00 & 0.96 & 0.93 \\
\hline HPC outlet total temperature & 1.02 & 1.00 & 1.00 & 1.00 & 0.95 & 0.90 \\
\hline HPT outlet total temperature & 1.10 & 1.03 & 1.03 & 1.00 & 0.91 & 0.83 \\
\hline LPT outlet total temperature & 1.11 & 1.04 & 1.04 & 1.00 & 0.91 & 0.83 \\
\hline $\mathrm{AB}$ outlet total temperature & 2.22 & 2.02 & 1.62 & 1.00 & 0.91 & 0.83 \\
\hline Combustor outlet temperature & 1.10 & 1.03 & 1.03 & 1.00 & 0.91 & 0.82 \\
\hline Mass flow rate of air & 1.00 & 1.00 & 1.00 & 1.00 & 0.96 & 0.88 \\
\hline Mass flow rate of fuel & 1.20 & 1.07 & 1.07 & 1.00 & 0.81 & 0.63 \\
\hline Throat area & 1.40 & 1.40 & 1.22 & 1.00 & 1.00 & 1.00 \\
\hline Mass flow rate of fuel $A B$ & 2.63 & 2.08 & 1.13 & 0.00 & 0.00 & 0.00 \\
\hline
\end{tabular}

$\mathrm{LPC}=$ low pressure compressor; HPC = high pressure compressor; $\mathrm{LPT}=$ low pressure turbine; $\mathrm{HPT}=$ high pressure turbine; $\mathrm{AB}=$ afterburner.

\section{METHODOLOGY}

The compressor characteristics map is the most influential input required for the off-design modeling of the engine. The characteristics map, along with the inlet performance map, determines the errors in the simulation output to a large extent. When engine is tested in ground based test beds, they are typically equipped with smooth-contoured bell mouth intakes. Since the experimental data set for this engine is available from ground test bed, the inlet total pressure loss is very low. The methodology adopted to tune the compressor characteristics map is given in the next section. 


\section{CHARACTERISTIC MAP TUNING}

Characteristic performance maps of both low and high pressure compressors of an engine very similar to the current engine were available in Akhmedzjanov (2000), and were digitized and scaled to the current engine specifications. Scaling laws for compressor and turbine maps are given by Jones (2007). An improved scaling method that enhances the accuracy of the simulation in an overall least squares sense was presented in Sankar et al. (2014). In this approach, instead of using single point scaling of component maps, as given by Jones (2007), the maps are scaled in a way that the sum of squares of errors in static pressure and total temperature at the HPC and the LPT exits are minimized. In the present work, instead of scaling the maps based on a single point (typically design point), the maps are scaled over the required operating range, using a scaling function, which operates on the original map to give the scaled map. The turbine maps are not tuned as they operate at a relatively constant pressure ratio in choked condition near the design point, as shown in Sankar et al. (2019)

The normalized map of LPC is displayed in Fig. 2 and a HPC map is shown in Fig. 3. The design beta value of both maps was found using an error minimization routine, though which, on the 100\% RPM line, the beta value that gave the design pressure ratio was chosen as the design beta.

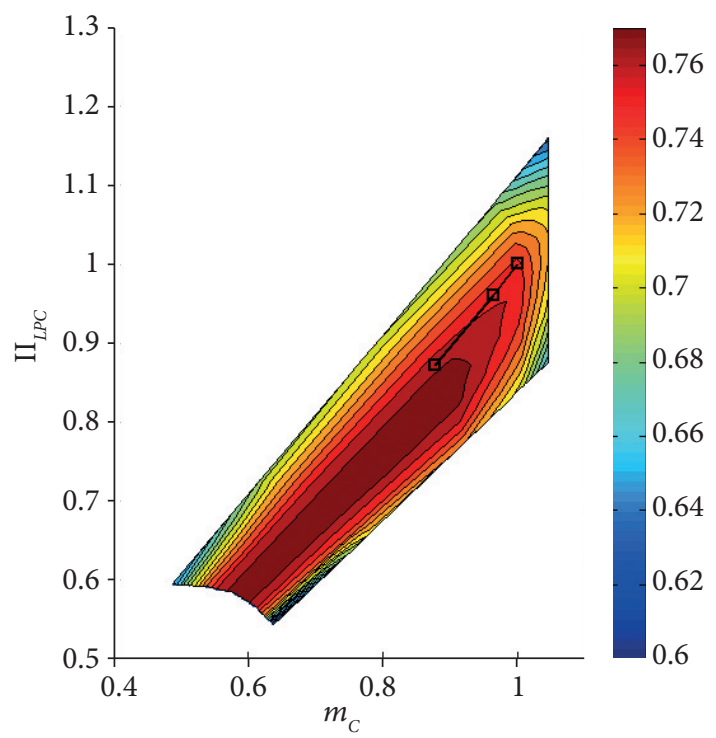

Figure 2. Original normalized LPC characteristics map. The markers indicate the location of design point, nominal rating, and $80 \%$ nominal rating.

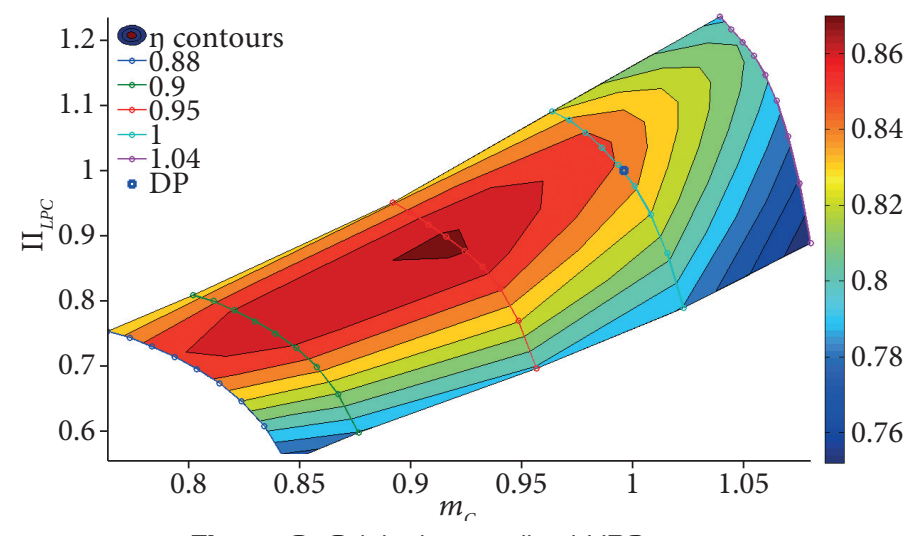

Figure 3. Original normalized HPC map. 
The multipoint tuning process is described for the efficiency contours of the LPC map. Similar process has been applied for HPC map so that it is consistent with the experimental data available. The points on the LPC map for the three off-design ratings can be identified using the mass flow rate and the pressure ratio of the LPC corresponding to these three ratings. The efficiencies for these operating points can be obtained from the efficiency contours of this map using interpolation techniques. Also, from inlet and exit gas properties of the LPC, (presented in Table 1), the isentropic efficiencies of the LPC can be calculated for these three off-design ratings. The two sets of efficiency values, one from characteristics map and one from the experimental data are compared in subplot of Fig. 4a, where the red markers indicate the efficiency values obtained from the map, in which an only single design point scaling has been applied. Hence, there is an exact match only at the design point and a marked difference in efficiencies at other two off-design ratings. A scaling function needs to be applied to the characteristics map to make it agree with the data at the other two off-design ratings. This scaling function is computed with RPM as the input argument and is plotted in Fig. 5. After the application of this scaling function on the single point scaled map, the resulting map agrees well with the experimental data as shown in the subplot of Fig. $4 \mathrm{~b}$. The efficiency contours on the LPC map after applying the multipoint scaling function are displayed in Fig. 6.
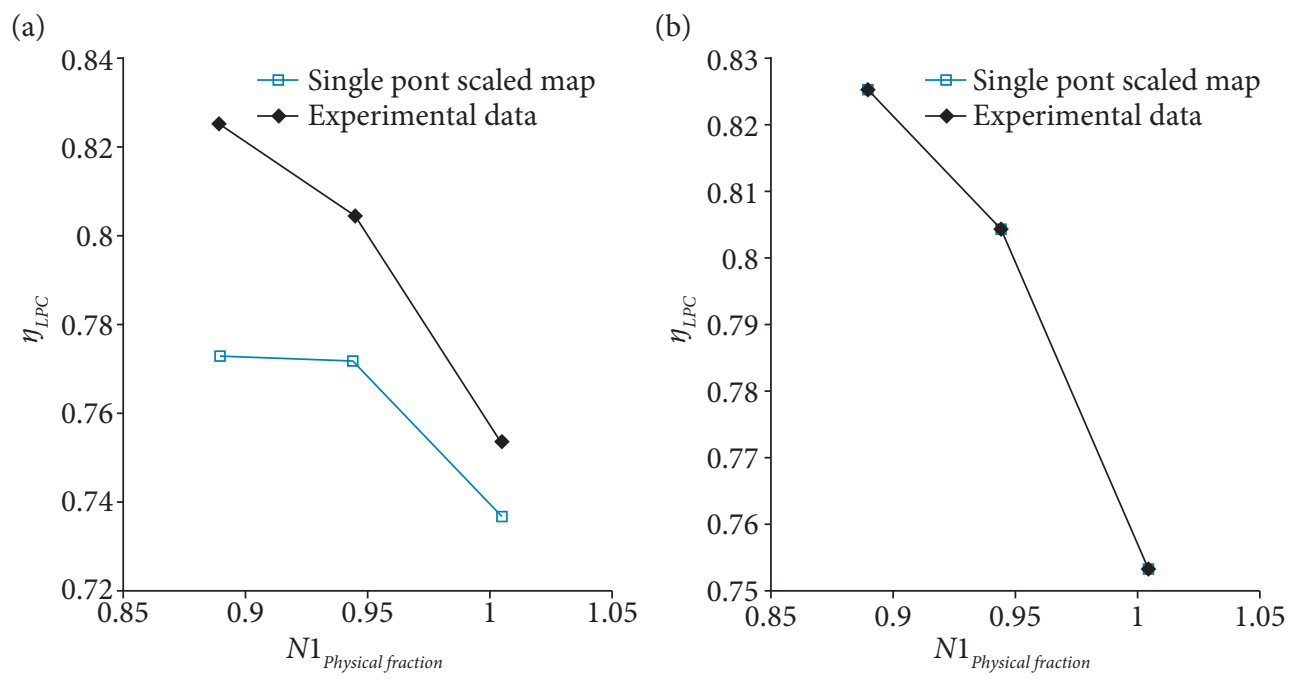

Figure 4. Comparison of efficiency values from characteristics map and experimental data before multipoint scaling (a) and after multipoint scaling (b).

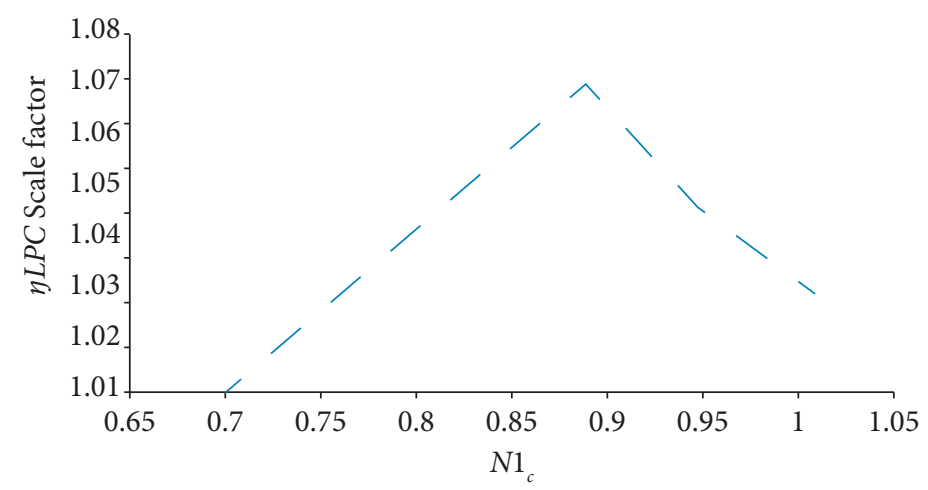

Figure 5. Scale factor to be applied to LPC efficiency map. 


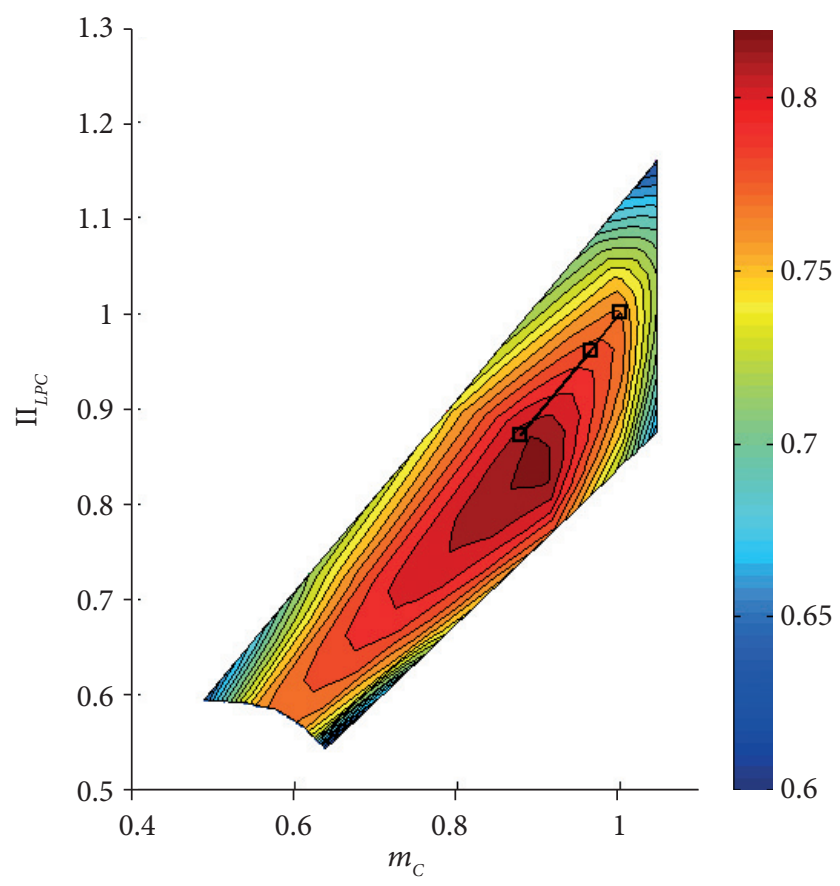

Figure 6. Multipoint scaled LPC map.

In addition to scaling of the efficiencies, it has to be ensured that the mass flow rate and the pressure ratio combinations of all the operating points occur at the respective RPM of the HPC. This is important since one of the significant effects of the reduction in the exhaust nozzle area is the change of N2 RPM for the same rating. The experimentally obtained operating line has been plotted on the HPC map presented in Fig. 7. The physical RPM corresponding to the off-design rating is typically available from the test bed, and is compared to the RPM from the HPC map in Table 2.

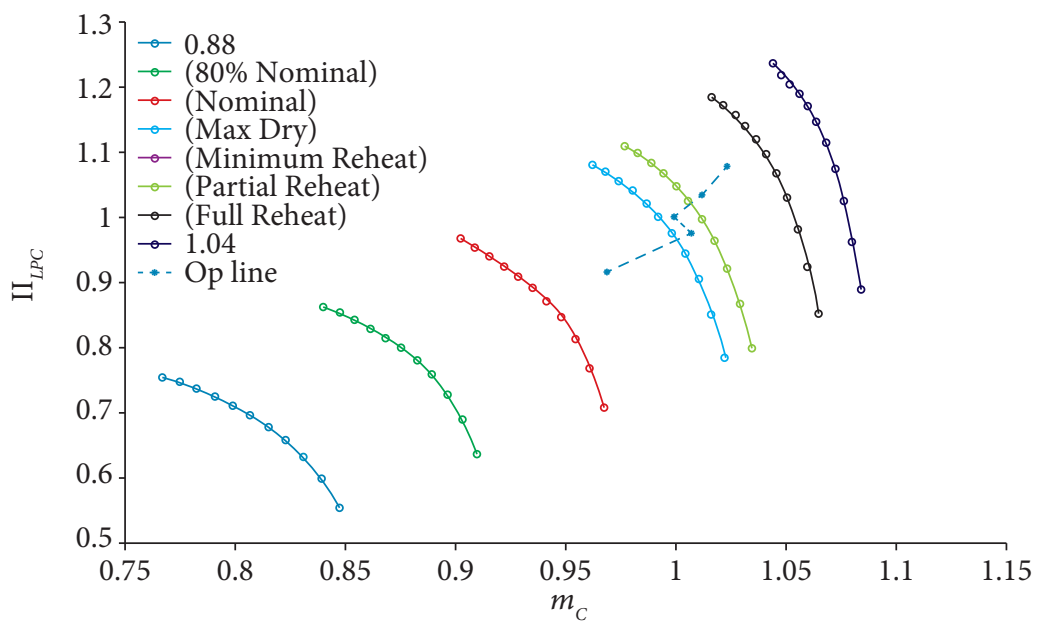

Figure 7.HPC map with experimentally obtained operating line before application scaling function on map. The figure shows that the experimental mass flow rate and pressure ratio do not lie on the respective RPM lines of the characteristics map. 
Table 2. N2 RPM (revolutions per minute) corresponding to off-design ratings from map and from experiments.

\begin{tabular}{|c|c|c|c|c|c|c|}
\hline Rating & Full reheat & $\begin{array}{c}\text { Partial } \\
\text { reheat }\end{array}$ & $\begin{array}{c}\text { Minimum } \\
\text { reheat }\end{array}$ & Max dry & $\begin{array}{c}\text { Nominal } \\
\text { nominal }\end{array}$ \\
\hline $\begin{array}{c}\text { Experimental RPM } \\
\text { (corrected) }\end{array}$ & 1.008 & 1.006 & 1.006 & 1.000 & 0.974 \\
\hline $\begin{array}{c}\text { RPM that matches pressure } \\
\text { ratio and mass flow rate from } \\
\text { the map }\end{array}$ & 1.017 & 1.008 & 1.008 & 1.000 & 0.993 \\
\hline \begin{tabular}{c} 
and \\
\hline
\end{tabular} & & & & 0.970 \\
\hline
\end{tabular}

A scale factor function similar to the LPC efficiency scaling function is applied to the HPC map to make the operating points fall on the respective constant RPM lines. This scale factor is plotted in Fig. 8. The HPC maps before and after application of the scaling function is displayed in Fig. 7 and Fig. 9, respectively. After tuning to match RPM, the map is again tuned to match efficiency values from test data, similar to the way LPC map was tuned. The tuned HPC map is presented in Fig. 10.

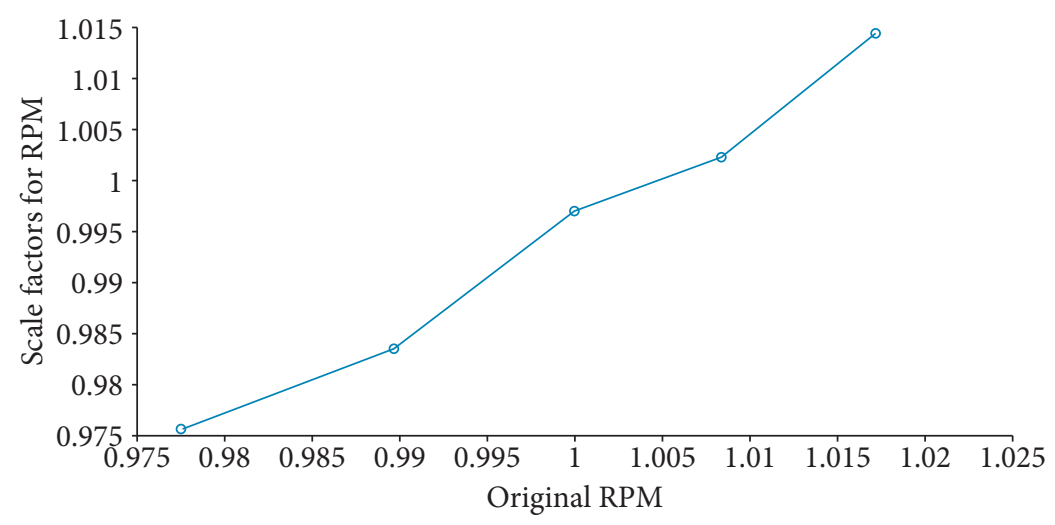

Figure 8. Scale factor to be applied to the HPC map RPM.

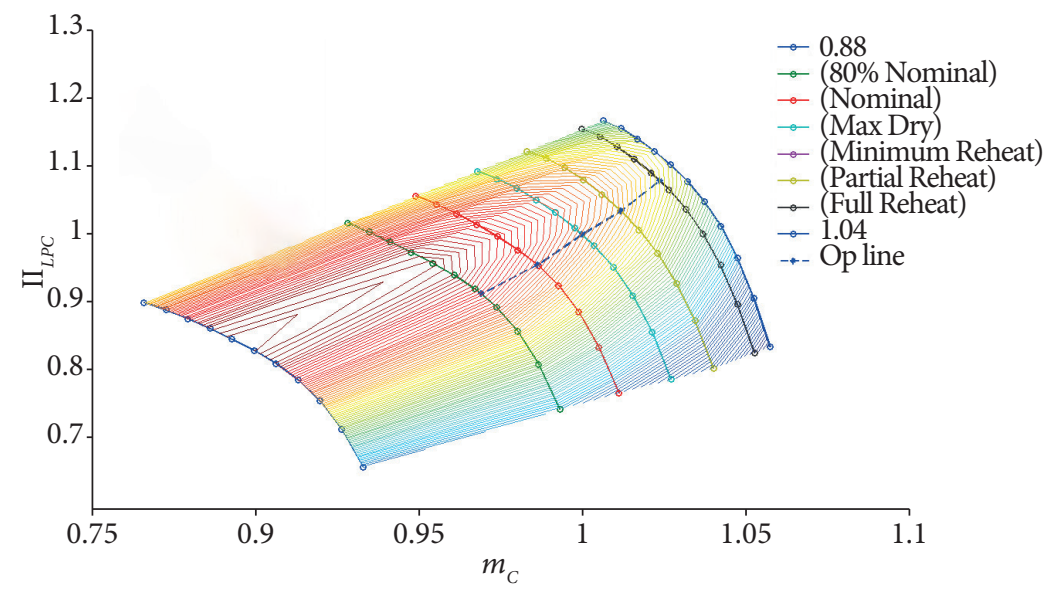

Figure 9. HPC map with experimentally obtained operating line after application scaling function on map. The figure shows that the experimental mass flow rate and the pressure ratio lie on the respective RPM lines of the characteristics map. 


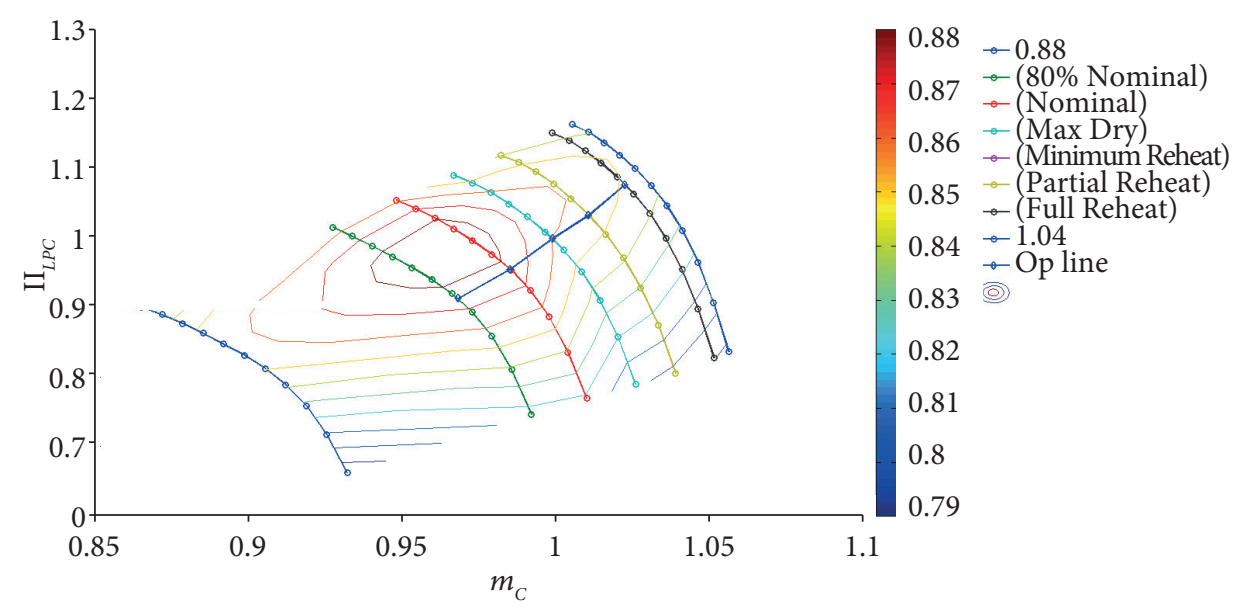

Figure 10. HPC map with efficiency contours scaled using multipoint scaling, so that efficiencies from the map agree with experimental data.

\section{DUCT PRESSURE LOSS FACTOR AND AB EFFICIENCY:}

Apart from tuning the component characteristics map of LPC and HPC using the available inlet and exit conditions of both the components, several duct pressure loss factors need to be estimated. These inter-component duct pressure losses are calculated using pressure measurements at various stations given in Table 1. AB pressure loss variation as a function of air mass flow rate is displayed in Fig. 11. Also, since AB fuel flow rate and temperature rise are known, the efficiency of $\mathrm{AB}$ can be calculated for a known lower heating value of fuel. The estimated combustion efficiency is shown in Fig. 12.

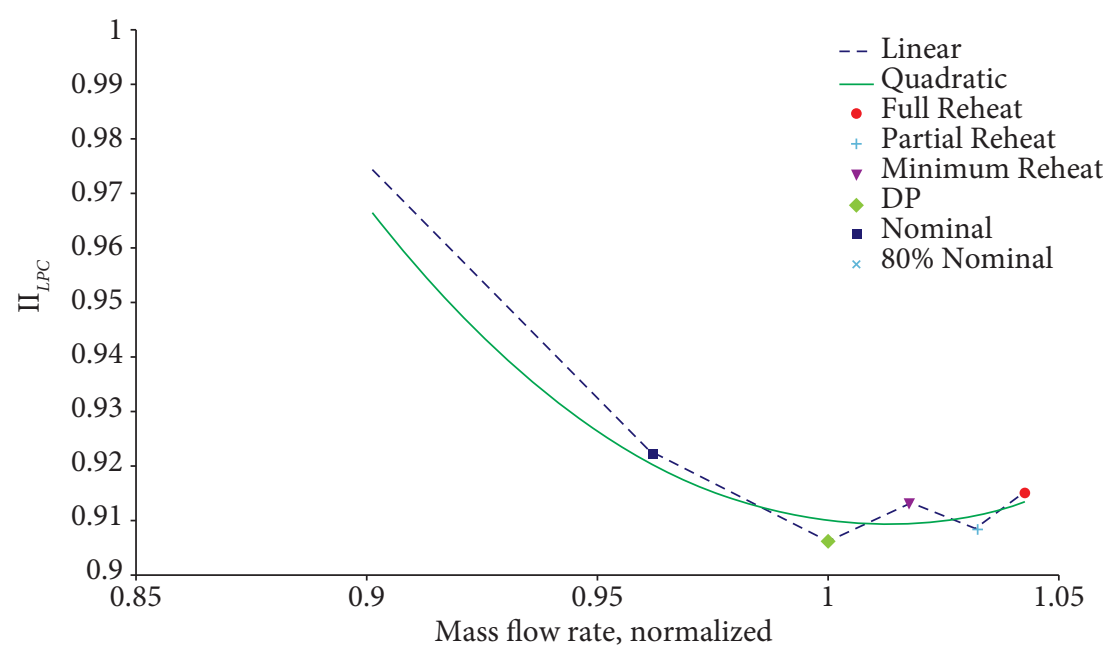

Figure 11. $A B$ pressure loss factor estimated as a function of normalised mass flow rate. 


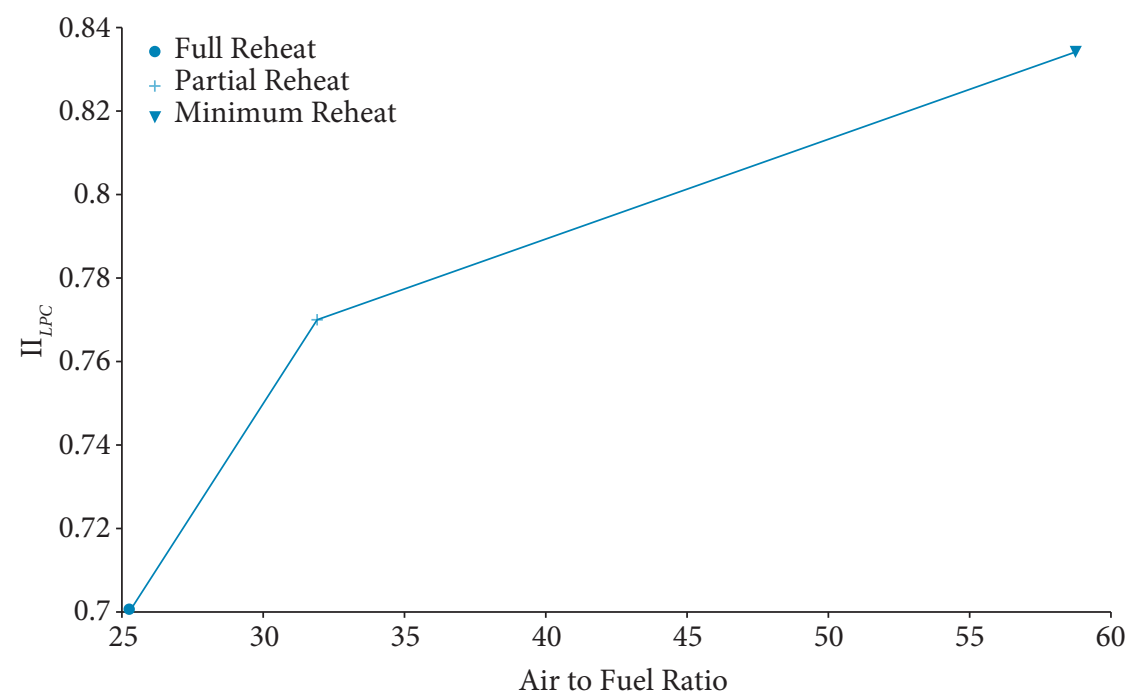

Figure 12. $A B$ efficiency as a function of air-to-fuel ratio.

\section{PERFORMANCE ANALYSIS USING SIMULATION MODEL}

The methodology followed in this work for off-design simulation is based on the matrix iterative technique detailed in Walsh and Fletcher (2004). This approach of simulation model development has earlier been applied to a single spool engine, as detailed in Sankar et al. (2013). This approach accounts for the variation of properties of the gas along the engine by appropriately changing the specific heat. This method can, hence, simulate different composition of gases along the engine, as done in Sankar et al. (2017). A brief summary of this approach is given as follows. The three parameters that determine the operating point of a twin spool engine are the operating point of low pressure and high pressure compressor $\left(\beta_{l p c}, \beta_{l p c}\right)$ and the main burner fuel flow

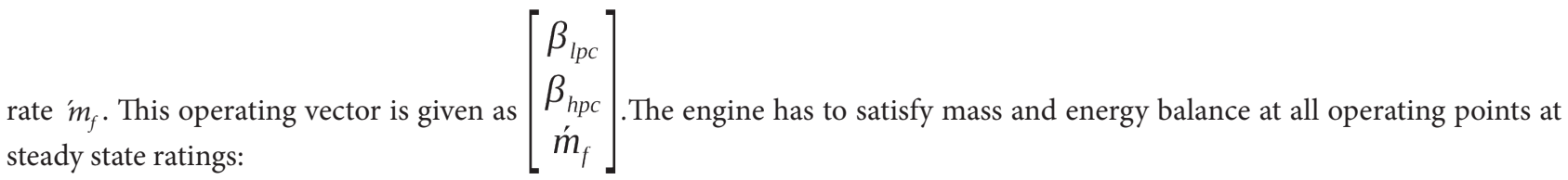
- Work extracted by the HPT = work consumed by the HPC;

- Work extracted by the LPT = work consumed by the LPC;

- Mass flow from combustor = mass flow into the HPT;

- Mass flow from HPT = mass flow into the LPT;

- Mass flow from LPT = mass flow into the convergent nozzle throat.

The energy balance is inherently satisfied at the two turbines as their pressure ratios are calculated from energy balance only. However, mass flow rate across the turbine for this pressure ratio may not be the mass flow rate pushed into it by the preceding component. In case mass balance is not satisfied, errors in mass flow occur at two turbines and at the nozzle. These errors have to be made nearly zero. The three errors that have to be minimized in order to obtain the operating vector are mass flow errors at high pressure and low pressure turbines $\left(m_{h p t}^{\text {error }}, m_{l p t}^{\text {error }}\right)$ and nozzle $m_{\text {nozzle }}^{\text {error }}$. This error vector is given as $\left[\begin{array}{l}\dot{m}_{h p t}^{\text {error }} \\ \dot{m}_{\text {lpt }}^{\text {error }} \\ \dot{m}_{\text {nozzole }}^{\text {error }}\end{array}\right]$. 
Each term of the Jacobian matrix is a partial derivative of a single error with respect to a single independent variable. This is calculated with the same simulation model by using small perturbation technique. Once the full matrix has been computed, a damped Newton-Raphson iterative scheme is used to find the operating vector in order to minimize the error vector. The Jacobian matrix, which gives the variation of error with respect to operating vector, is re-evaluated during each iteration due to the non-linearity of the problem. The change in guess of the operating vector is then calculated by solving Eq.1:

$$
\left[\begin{array}{ccc}
\frac{\partial \dot{m}_{h p t}^{\text {error }}}{\partial \beta_{l p c}} & \frac{\partial \dot{m}_{h p t}^{\text {error }}}{\partial \beta_{h p c}} & \frac{\partial \dot{m}_{h p t}^{\text {error }}}{\partial \dot{m}_{f}} \\
\frac{\partial \dot{m}_{l p t}^{\text {error }}}{\partial \beta_{l p c}} & \frac{\partial \dot{m}_{l p t}^{\text {error }}}{\partial \beta_{h p c}} & \frac{\partial \dot{m}_{l p t}^{\text {error }}}{\partial \dot{m}_{f}} \\
\frac{\partial \dot{m}_{\text {nozzle }}^{\text {error }}}{\partial \beta_{l p c}} & \frac{\partial \dot{m}_{\text {nozzle }}^{\text {error }}}{\partial \beta_{h p c}} & \frac{\partial \dot{m}_{\text {nozzle }}^{\text {error }}}{\partial \dot{m}_{f}}
\end{array}\right]\left[\begin{array}{c}
\beta_{l p c} \\
\beta_{h p c} \\
\dot{m}_{f}
\end{array}\right]=\left[\begin{array}{c}
\dot{m}_{h p t}^{\text {error }} \\
\dot{m}_{l p t}^{\text {error }} \\
\dot{m}_{\text {nozzle }}^{\text {error }}
\end{array}\right]
$$

For a given off-design point, once the errors have reduced to a value specified by the convergence limit, the operating vector for this error condition is saved as the operating vector for the particular operating point. The fuel flow rate and the compressor operating points of HPC and LPC have been obtained for this operating point. For the next operating point, which is usually at a lower RPM, the values from the current operating point are used as a starting guess.

The results of the simulation are presented in Fig. 13. This figure shows the operating line of the LPC and the HPC on their respective maps. It can be seen, from the operating line slope that the HPC moves closer to surge at higher ratings of the engine. The constant RPM lines are shown in multiple colors from 70 to $110 \%$ of design speed. The operating line obtained from the simulation is shown as a continuous black line. As the engine accelerates from cruise rating to max dry rating through the nominal rating, pressure ratio and mass flow rate increase almost in a linear fashion. After reaching $100 \%$ of design speed, when the reheat is engaged in the after burner, the RPM is maintained constant while there is a small dip in the pressure ratio. The LPC operating point for both minimal reheat rating and partial reheat rating

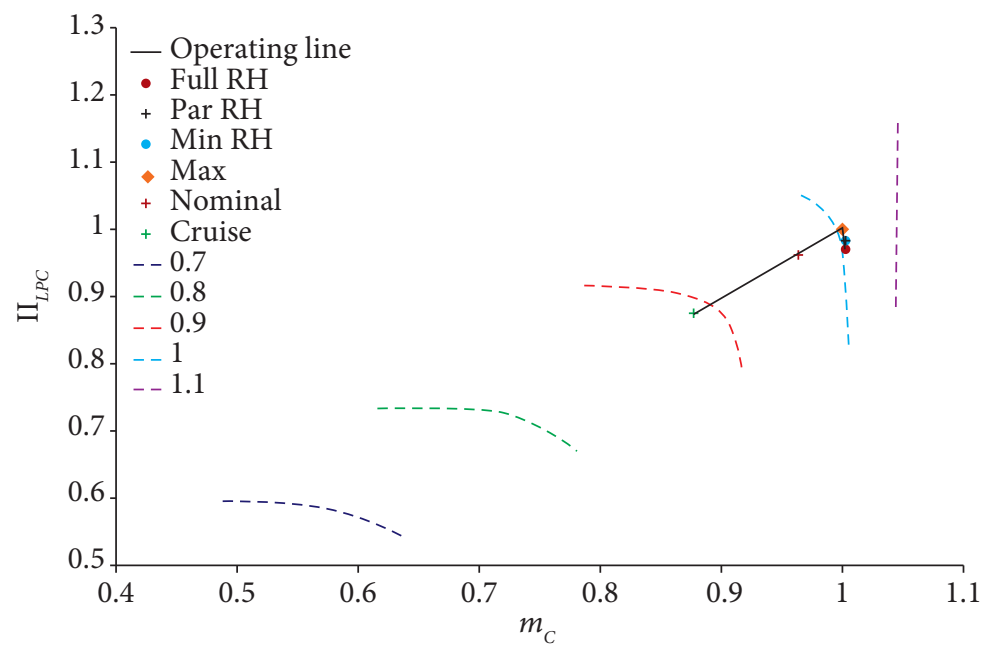

Figure 13.Characteristic maps with simulated operating line(shown in black). Also experimental operating points corresponding to different ratings are shown with markers. 
is the same, since there is no change in the corrected gas path parameters up stream of the choked LPT NGV during these two ratings. However, during the full reheat rating, the main burner fuel flow rate is slightly increased from its value at partial reheat, resulting that the main burner exit temperature and the specific volume increases, which causes the HP spool to accelerate further to pass the mass flow coming in from the combustor. This acceleration of HP spool at the full reheat rating can be clearly seen in Fig.14. In this plot, operating points for minimum and partial reheat are coincident, but full reheat is at a higher RPM.
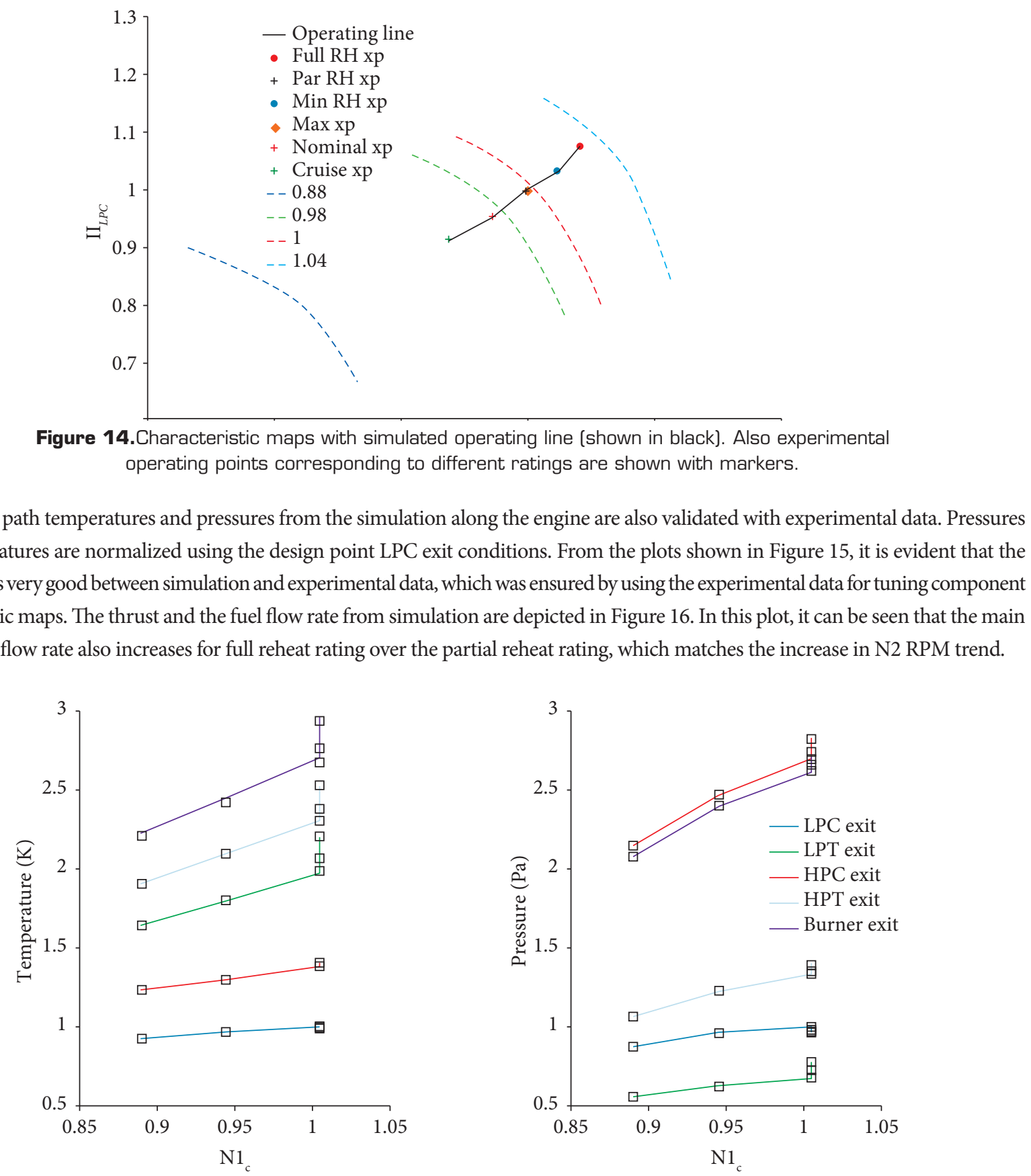

Figure 15. Major gas path parameters from simulation, validated with test bed data. 

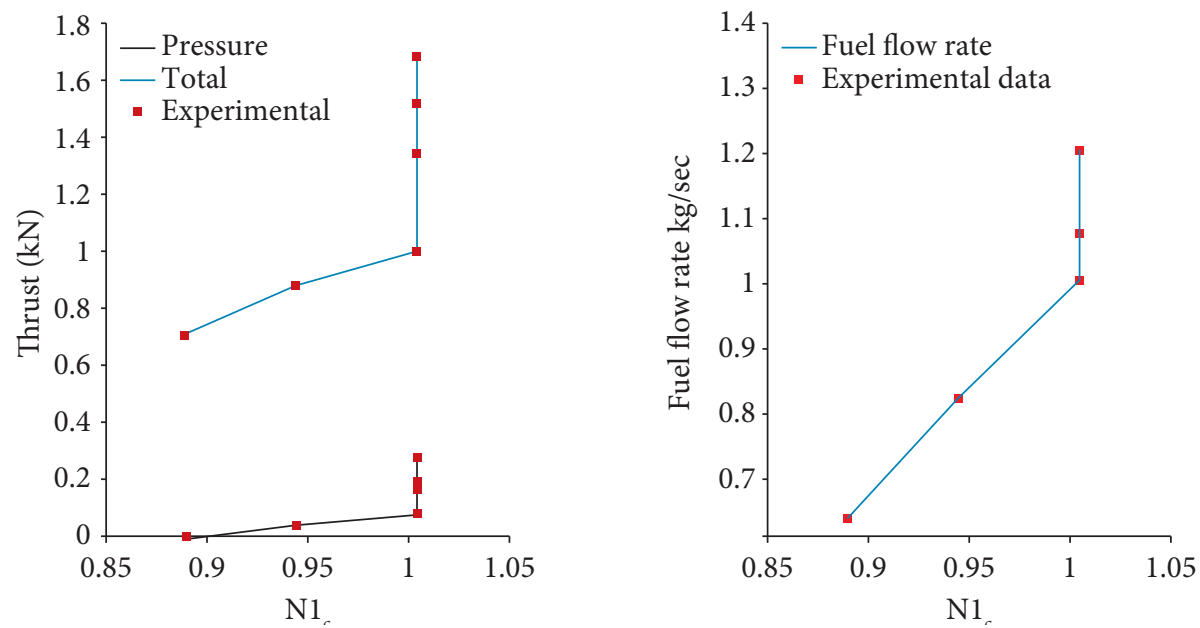

Figure 16. Major performance parameters from simulation, validated with test bed data. Total thrust refers to summation of pressure and momentum thrust, obtained from simulation.

\section{EFFECT OF CHANGE IN EXHAUST NOZZLE AREA IN A HEALTHY ENGINE}

This validated simulation model is now used to study the effect of reduction of the exhaust nozzle area in a healthy engine. Said area is the throat for convergent nozzles. When the exhaust nozzle area is reduced by $1 \%$ in all reheat ratings, the main burner fuel flow rate and thrust is increased, as presented in the Fig. 17. The increased fuel flow rate leads to a higher combustor exit temperature, which requires higher N2 RPM to satisfy mass balance at the HPT. The N2-corrected RPM increase is seen in Fig. 18.

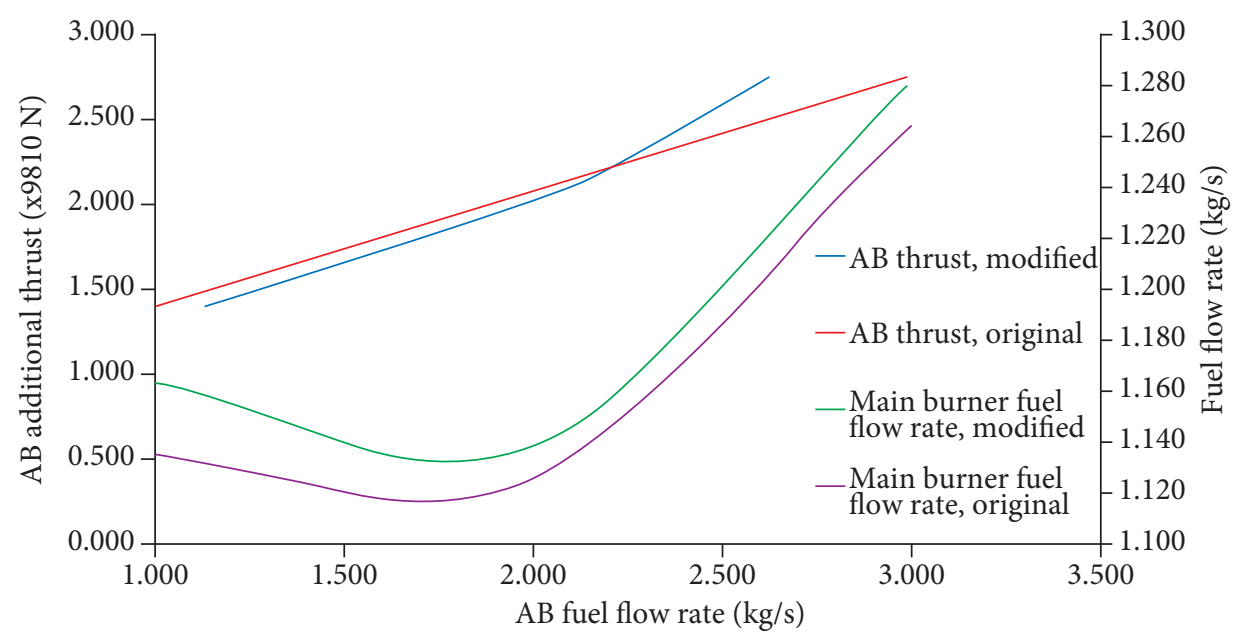

Figure 17. Thrust and main burner fuel flow rate variation with $A B$ fuel flow rate when default and modified area schedules are used. 


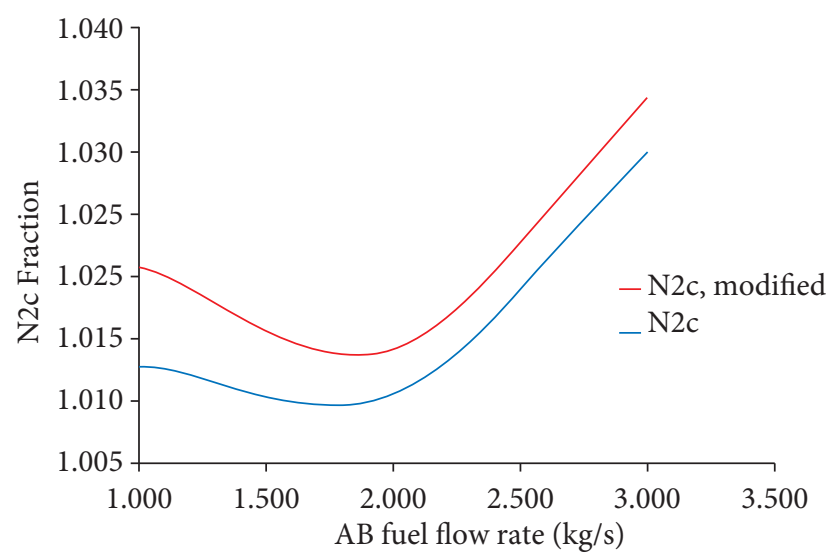

Figure 18. N2c variation with $A B$ fuel flow rate when default and modified area schedules are used.

\section{EFFECT OF CHANGE IN EXHAUST NOZZLE AREA IN A LEAKY ENGINE}

The nozzle flaps are provided for varying the exhaust area during reheat operation, and slide over each other during convergence. Due to warping at high temperatures in reheat rating, the nozzle flaps do not seal the flow properly and cause leakage. From simulation using the validated model, it has been calculated that a $1 \%$ leakage of air mass flow at full reheat rating in the nozzle flaps causes reduction in thrust $(-1.4 \%)$, N2-corrected RPM $(-0.6 \%)$, main burner fuel flow rate $(-1.9 \%)$, and combustor exit temperature $(-1 \%)$. As a quick remedy in maintenance station, the exhaust nozzle area is typically reduced to compensate for the reduction of thrust. A proportionate decrease in the exhaust nozzle area brings back the LPT and HPT to their original pressure ratios. Hence, both the compressors return to their original operating points. However, simply maintaining original operating points for both compressors results in a reduced thrust, as the leaked flow does not contribute to momentum thrust from the engine. To get back the original levels of thrust, a minimal increase in fuel flow rate, $\mathrm{N} 2 \mathrm{c}$ and combustor exit temperature are required above the healthy engine values. The trend of these increases is similar to that shown in the previous section.

\section{CONCLUSION}

Air leakage in the exhaust nozzle flaps of the convergent nozzles is often noticed during the overhaul of legacy turbojets. To correct for the leakage, the exhaust nozzle area is reduced. For quantifying the effect of this leakage and the corrective measures required, it is necessary a validated performance model, which, by its turn, requires compressor characteristics maps for LPC and HPC, not usually provided by the manufacturer. In this work, experimental data from test bed was used to tune the characteristics map of both compressors, using multipoint scaling methods. Using estimated duct pressure loss values and tuned characteristic maps, an engine specific performance model was developed, applying matrix-based iterative techniques. This model was validated with the original experimental data for design point and off-design ratings, along with reheat ratings. Using this model, the effect of reduction in exhaust area of the convergent nozzle was first analyzed. It was observed that reduction of exhaust nozzle area forces the high pressure spool of the engine to accelerate and go towards the surge. As a linked behavior, the HPT inlet temperature increases, which reduce the life of the hot end components. A reduction of exhaust area is often attempted to compensate for reduced turbine inlet and jet pipe temperatures, due to leaky nozzle flaps. Reducing the nozzle area to get back original design thrust with leaky nozzle flaps increases the turbine inlet temperature beyond design value, and also reduces the surge margin of the HPC. At present, the leakage of hot gases is detected using thermal imaging cameras 
at the overhaul station. This approach indicates only the presence of leakage and does not quantify it. Actual measurement of the inlet and exhaust mass flow will enable us to calculate the mass flow rate of leakage air and correlate it with experimentally measured thrust decrease. This activity will aid in improving the accuracy of the simulation model, by making possible to estimate the allowable nozzle area change.

\section{AUTHOR'S CONTRIBUTION}

Conceptualization, Gouda G and Sankar B; Methodology, Gouda G and Sankar B; Validation, Iyengar V and Soumendu J; Supervision, Iyengar V and Soumendu J; Writing - Original Draft, Sankar B; Writing - Review and Editing, Sankar B.

\section{REFERENCES}

Akhmedzjanov AM (2000) Design of aircraft gas turbine engines: Book for higher educational institutions. Moscow: Mashinostroenie, p. 405.

Bechini G (2007) Performance diagnostics and measurement selection for online monitoring of gas turbines (PhD thesis) Cranfield: University Cranfield.

Cohen H, Rogers G, Saravanamuttoo HIH (2001) Gas turbine theory. 5th ed. London: Longman Group Limited. https://doi. org/10.1017/S0001924000066203

Fasching WA, Stricklin R (1982) Summary report for CF6 jet engine diagnostics program. NASA contractor report. NASA CR 165582.

Isaac BD (1992) Engine performance and health monitoring models using steady state and transient prediction methods. AGARD Lecture series 183. North Atlantic Treaty Organization.

Jones SM (2007) An introduction to thermodynamic performance analysis of aircraft gas turbine engine cycles using the numerical propulsion system simulation code. NASA/TM - 2007-214690.

Kerrebrock JL (1992) Aircraft engines and gas turbines. 2nd ed. Cambridge: MIT Press. ISBN: 9780262111621

Li YG (2002) Performance analysis based gas turbine diagnostics: A review. Proc Inst Mech Eng, Part A216(5). https://doi. org/10.1243/095765002320877856

Li YG, Pilidis P, Newby MA (2006)An adaptation approach for gas turbine design point performance simulation. J Eng Gas Turbines Power 128. doi: https://doi.org/10.1115/1.2136369

Mattingly JD (2006) Elements of propulsion: Gas turbines and rockets. Blacksburg: AlAA Education Series. https://doi. org/10.2514/4.103711

Saravanamuttoo HIH (May 1992) Overview on basis and use of performance prediction methods. AGARD Lecture Series 183. North Atlantic Treaty Organization.

Sankar B, Subramanian T, Shah B, Vanam V, Jana S, Ramamurthy S, Satpathy R, Sahoo B, Yadav S. (2013) Aerothermodynamic modeling and gas path simulation for a twin spool turbo jet engine. Paper presented ASME GT India Conference; Bangalore, India. https://doi.org/10.13140/RG.2.1.1201.8401

Sankar B, Shah B, Ramamurthy S, Satpathy RK, Yadav S (2014) Tuning of component characteristics maps in off-design simulation of gas turbines. Paper presented International Conference on Smart Materials, Structures and Systems; Bangalore, India.

Sankar B, Shah B, Satpathy RK, Gouda G, Jana S (2015) Gas path parameter degradation estimation in a turbojet during long test. Paper presented National Conference On Condition Monitoring (NCCM-2015). Naval Science and Technological Laboratory; Visakhapatnam, India.

Sankar B, Shah B, Jana S, Ramamurthy S, Satpathy RK, Gouda G (2016) Design point parameter estimation of a legacy twin spool turbojet engine for health monitoring. J AeS I68(2):101-109. 
Sankar B, Shah B, lyengar V, Jana S, Gouda G (2017) Water ingestion study in a twin spool turbojet engine. Paper presented National Conference On Condition Monitoring (NCCM-2017). IGCAR; Kalpakkam, India.

Sankar B; Danish TH (2018) Performance trends of a generic small gas turbine engine, Paper presented National Aero Propulsion Conference (NAPC 2018). IIT Kharagpur; West Bengal, India.

Tsoutsanis E (2010) Performance adaptation of gas turbines for power generation applications (PhD thesis). Cranfield: Cranfield University.

WalshPP, FletcherP(2004)Gasturbine performance. 2nd ed. Oxford: BlackwellScience. https://doi.org/10.1002/9780470774533 